\title{
Experimental Lagochilascariosis: Histopathological Study of Inflammatory Response to Larval Migration in the Murine Model
}

\section{Amélia Regina Semerene, Ruy de Souza Lino Junior, Jayrson Araújo O liveira, Albino Verçosa Magalhães*, Mariane Martins Araújo Stefani, Alverne Passos Barbosa, Dulcinéa Maria Barbosa Campos/ ${ }^{+}$}

\author{
Departamento de Microbiologia, Imunologia, Parasitologia e Patologia, Instituto de Patologia Tropical e Saúde Pública, \\ Universidade Federal de Goiás, Rua 235 c/ 1ª Avenida s/n, Setor Leste Universitário, 74605-050 Goiânia, GO, Brasil \\ *Departamento de Patologia, Faculdade de Medicina, Universidade de Brasília, Brasília, DF, Brasil
}

The goal of this study was to investigate the pattern of inflammatory response induced by Lagochilascaris minor in murine experimental model. For this purpose 115 mice were given 1000-3000 L. minor infective eggs "per os" and 51 uninfected mice were considered as controls. Four hours post-inoculation (PI), 3rd stage larvae were seen passing through the mucosa of terminal ends of small intestine. Six hours PI larvae were observed as an embolus inside the portal vein and also migrating through the liver parenchyma. During the first $24 \mathrm{~h}$ larvae-containing eggs of L. minor were observed in the lumen of intestinal tract. Two days PI larvae were seen migrating through lung parenchyma associated with an initial neutrophilic perivasculitis. From the 13th day of this experimental study, L. minor larvae were found mainly in skeletal muscles, in the center of granulomas. Concentric fibrosis with mixed inflammatory infiltrate involved the larvae after the 47th day PI, persistently. This experimental murine study with $\mathrm{L}$. minor indicated that the 3rd stage larvae penetrated via ileum-cecal mucosa reaching the liver and probably other tissues through the hematogenic via. Throughout its pathway the larvae induced a granulomatous reaction, with abundant polimorphonuclear cells.

Key words: Lagochilascaris minor - experimental infection - inflammatory response

Lagochilascaris minor (Leiper 1909) affects human tissues, especially in the head and neck, and gives rise to a rather rare nosological diagnostic condition. For the differential diagnosis other diseases such as paracoccidioidomycosis, tuberculosis, actinomycosis, and leishmaniasis must be considered. The definitive diagnosis can only be made when it is possible to identify the parasite in the tissue biopsy or in the material obtained by scraping or puncture (Farah et al. 1995). Worldwide Brazil leads the number of patients infected with $L$. minor (Fraiha et al. 1989).

Lagochilascariosis is a polymorphic disease in which symptoms depend on the tissue localization, on the parasite burden and on the host immune response. The lesions which can be fistulated or not, keep the parasite in various stages of maturation and self- infection can occur (Fraiha et al. 1989, Campos et al. 1992).

It has been originally hypothesized by Smith et al. (1983) that both an intermediate rodent host and a definitive carnivorous host would participate in the L. minor life cycle. According to this, the definitive host would become infected by ingesting raw or inadequately cooked meat of a wild rodent. The experimental life cycle of $L$. minor has been described employing mouse model as the

Financial support: Conselho Nacional de Desenvolvimento Científico e Tecnológico, process 40.0254/95

Corresponding author: Fax: +55-62-521.1839. E-mail: dmcampos@iptsp.ufg.br

Received 4 December 2003

Accepted 24 May 2004 intermediate host and domestic cat as the definitive host (Campos et al. 1989a,b, 1992). These previous studies have described the morphological characterization of all L. minor stages, the route of the parasite in each host and have confirmed the original life cycle hypothesis by Smith et al. (1983).

The main goal of this study was to describe the kinetics of the inflammatory response induced by L. minor in mice from the larvae hatching in the intestine until its encapsulation in the muscles.

\section{MATERIALS AND METHODS}

Parasites - Uterine eggs collected from female L. minor obtained from patients (named ACS 22 years old and HGS, 11 years old, from Conceição do Araguaia and Marabá, PA, respectively) were maintained in culture in formaldehyde solution at $1 \%$ at room temperature for 30 days so that the infective larvae could develop (Campos et al. 1992). This suspension of embryonated eggs was transferred to graduate centrifuge tubes and after regulating the volume, three equal amounts of $0.001 \mathrm{ml}$ were drawn out and the eggs counted on microscopic slides, to determine the concentration of eggs per ml (Campos et al. 1992).

Animals and experimental infection - Mice C57BL/6 lineage $(n=166)$ of both sexes, aged between 35 and 60 days were employed; 115 mice were inoculated orally, using an infecting suspension of 1000 to $3000 \mathrm{~L}$. minor eggs per animal. Fifty-one mice that were not infected were used as controls. After the inoculation, animals were sacrificed in groups that consisted of 3 inoculated mice and 2 control animals, at intervals of 10 min during the first hour; hourly until $6 \mathrm{~h}$ after inoculation; then at 12,18 , and $24 \mathrm{~h}$; 
daily during the first week; weekly during the first month; and finally at 120 days after inoculation. After sacrificing, each animal was necropsied, followed by macroscopic and microscopic examination of the viscera, skeletal musculature, skin and subcutaneous layers. Histopathological sections were stained using Hematoxylin-Eosin and observed under the light microscope.

This project was approved by the Ethics Committee on Animal Research from the Federal University of Goiás.

\section{RESULTS}

Larval migration - In mice orally inoculated with $L$. minor infecting eggs, hatched larvae in the gastrointestinal tract in the first $24 \mathrm{~h}$ PI, confirming successful inoculation (Fig.1). Four hours after inoculation, early thirdstage larvae were first observed passing through the mucosa in distal portions of the small intestine and cecal mucosa (Fig. 2). Larvae were seen both close to the mucosal surface and deeper in the lumen of vessels, after crossing the mucosa (Fig. 3). Six hours after inoculation, larvae were detected embolizing branches of the portal vein (Fig. 4). At the same time, free larvae were observed migrating through the hepatic parenchyma, either close or distant from the portal space (Fig. 5). Twenty-four hours after inoculation, integral free third-stage larvae were observed migrating through the pulmonary parenchyma (Fig. 6).

From the second to the 13th day after inoculation, larvae were sporadically observed. Only small fragments of larvae were seen in the lungs, on the 6th day after inoculation. On the 13th day after inoculation, third-stage larvae were seen in the lungs and skeletal musculature. The presence of mixed inflammatory infiltrate in the heart, pancreas and kidneys was considered to be an indirect sign of larvae migration; however, we have not observed the direct evidence of the parasite.

Sixteen days after inoculation, $L$. minor larvae were seen in the center of granulomas in the skeletal musculature, and were not observed in other organs or tissues. Nineteen days after inoculation, larvae were observed in the center of granuloma in the liver, in perisplenic fat, in skeletal musculature and in the renal parenchyma.

Thirty-three days after inoculation, as well as at 40 and 47 days PI, the larvae were seen in the skeletal musculature. At this time point evidences of somatic larval growth were seen. Sixty-one days after inoculation, $L$. minor was seen in the center of lesions in the skeletal musculature (Fig. 7), as well as subcutaneous layers and the peri-renal fat. On the last time point examined, 120 days after inoculation, $L$. minor larvae were seen in the centers of granulomas located in the lungs, pancreas, skeletal musculature and in subcutaneous tissue.

Macroscopic alterations - Small $(<1 \mathrm{~mm}$ diameter) white-yellowish nodules were first seen disseminated in the subcutaneous tissue and skeletal musculature on the 47th day PI. Sixty-one days PI, nodules were bigger (diameters $\sim 1 \mathrm{~mm}$ ). A hundred and twenty days PI, nodules, mostly with $1.5 \mathrm{~mm}$ diameter, were disseminated in the skeletal musculature (Fig. 8). Few bigger lesions of $\sim 6 \mathrm{~mm}$ diameter were seen, and when perforated, drained a yellowish purulent substance.
Inflammatory response - Inflammatory infiltrates were first observed in the portal entrance, in the chorion mucosa of the final portion of the small intestine and the cecum. In these tissues, from the 4th to 24th h PI, discrete accumulations of polymorphonuclear neutrophils were observed, either surrounding L. minor larvae or not. Thereafter, between 6 and $24 \mathrm{~h}$ after inoculation, the main findings were: hydropic-vacuolar and fatty microdroplet alterations and necrosis of the hepatocytes. These phenomena were very evident in the portal space where thirdstage larvae were frequently observed.

After 2 days infection, perivasculitis and vasculitis were frequent, initially in discrete form, close to the pulmonary parenchyma following the migrating third-stage larvae. Small and medium-sized venous vessels exhibited polymorphonuclear neutrophils either paving or permeating the vascular wall and in the perivascular tissue. In some tissues, deposition of fibrinous material and dissolution of the wall continuity (Figs 9, 10) were observed. Simultaneously, lymphoid hyperplasia, characterized by lymphoid follicles with expanded germinative center, was seen in the spleen.

In almost all inoculated mice, pulmonary alterations such as perivasculitis and vasculitis persisted until the last time point of the experiment, day 120 PI. Differences in the severity of the infiltrate and cell populations present, were verified. Perivasculitis and vasculitis became progressively more severe, sometimes obliterating the vascular lumen (Fig. 11).

On the 6th day after inoculation, increased numbers of eosinophils were seen in the perivascular inflammatory infiltrate of the pulmonary parenchyma. The lung was the only tissue to show evident alterations between the 2nd and 10th day PI. Moderate perivasculitis was observed in the perisplenic adipose tissue on the 5th day after inoculation.

On the 13th day after inoculation, unorganized granulomatous reactions were observed in the lungs. These lesions were characterized by intense diffuse infiltrate of giant multinucleated cells with fringing material in the cytoplasm located in the alveolar lumen. Perivascular inflammatory infiltrates containing eosinophils were also seen. Simultaneously, perivasculitis was detected in the heart. There was also a discrete non-specific inflammatory reaction of mixed-cell populations in the skeletal musculature, in the peri-renal fat and in the pancreatic tissue. For the first time a granulomatous reaction was observed inside the renal parenchyma. This reaction contained mononuclear, polymorphonuclear, giant multinucleated cells, larval fragments and fibroblasts.

Sixteen days PI, the lesions exhibited the same histopathological pattern in the renal parenchyma as previously described. This pattern corresponded to an intermediate stage in the organization of the inflammatory response, which was named "the early nodule". Nineteen days after inoculation, the lesions resembled early nodules, with signs of initial fibrosis containing several larvae fragments (Fig. 12). Amorphous eosinophilic material was sometimes seen around the larvae.

Over the period of the experimental infection, somatic growth of the third-stage larvae located at the centers of 
granulomas was observed. The lesions developed with concentric fibrosis, thus delimiting the nodules, interspersed with delicate blood vessels, xanthomatous histiocytes, giant multinucleated and polymorphonuclear cells. In most cases the centers of these lesions contained several well- preserved body sections of third-stage larvae and amorphous acidophilic material. This histological pattern persisted from the time it first appeared, around 40 days PI, until the last time point of experimental infection (120 days PI). Based on these observations this structured was named
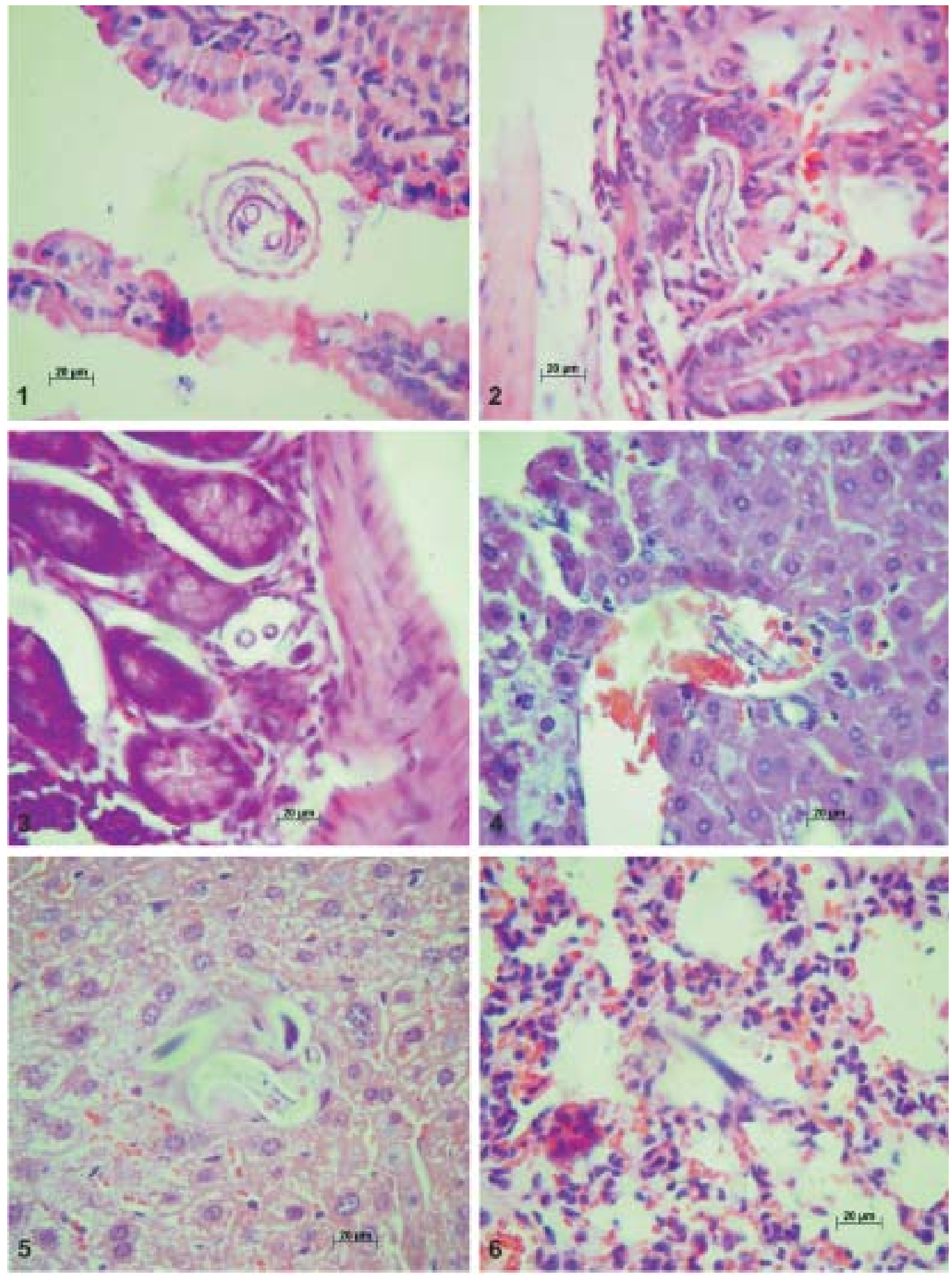

Lagochilascaris minor (400x). Fig 1: view of the larval egg among the intestinal villi, $12 \mathrm{~h}$ after inoculation. Fig 2: view of the third-stage larvae crossing the cecal mucosa, $4 \mathrm{~h}$ after inoculation. Fig 3: larvae in the ileum wall, inside a lymphatic vessel of the submucosa, $6 \mathrm{~h}$ after inoculation. Fig 4: larvae embolizing the intrahepatic portal system, $6 \mathrm{~h}$ after inoculation. Fig 5: larvae migrating through the hepatic parenchyma, $6 \mathrm{~h}$ after inoculation. Fig 6: third-stage larvae migrating through the pulmonary parenchyma, $24 \mathrm{~h}$ after inoculation. 

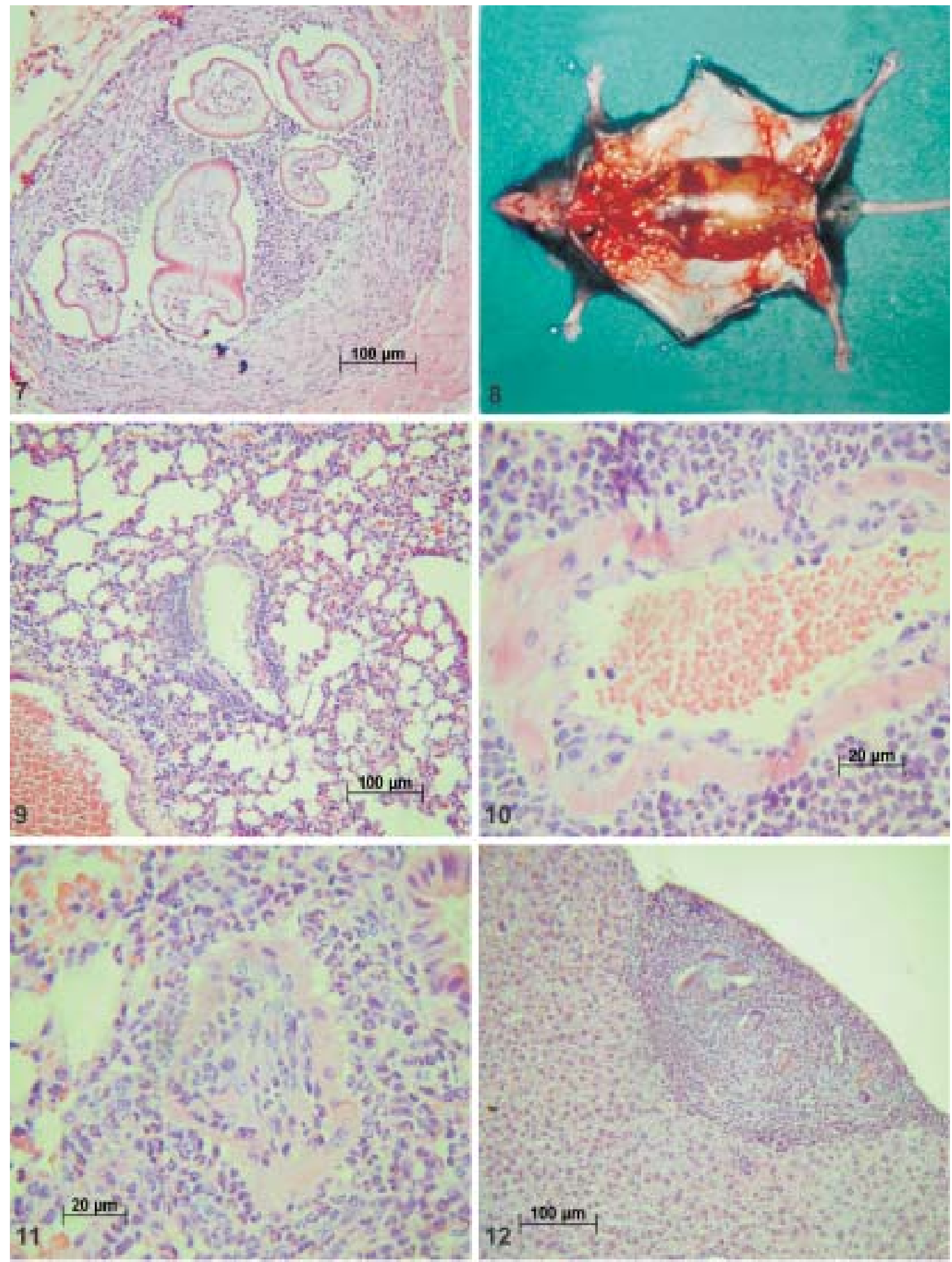

Lagochilascaris minor. Fig 7: larvae inside a mature nodule in skeletal muscle tissue, 61 days after inoculation. It has cystic appearance, consisting of a fibrous wall and necrotic center (100x). Fig 8: macroscopic appearance of the nodules, 120 days after inoculation. Fig. 9: pulmonary vessel with dissolution of wall continuity, deposition of fibrinous material and drainage of liquid and cells, $24 \mathrm{~h}$ after inoculation (400x). Fig. 10: pulmonary vessel exhibiting leukocytes migrating through the wall, with dissolution of its continuity and intense perivasculitis, 6 days after inoculation (400x). Fig. 11: obliterating vasculitis and intense perivasculitis, with evident eosinophils, 13 days after inoculation (400x). Fig 12: larvae surrounded by giant multinucleated cells, epithelioid cells, and mononuclear and polymorphonuclear cells, constituting an early nodule in the liver, 19 days after inoculation (100x). 
"the mature nodule" (Fig. 6). During the entire time of this experimental study, neither lesions nor larvae were observed in vessels or tissue of the central nervous system.

\section{DISCUSSION}

This study characterizes the histology of the inflammatory response to third stage larvae of L. minor during the first 4 months of experimental mice infection. PMN neutrophils were seen in all lesions from the second day PI to the end of the study. Our findings indicate that the granulomatous reactions comprise the mature inflammatory response to this parasite. We hypothesize that the parasite and the irritant substances it may secrete, induce a strong inflammatory response leading to tissue invasion, abscess formation promoting migration to distant organ structures.

The early inflammatory reaction to the third-stage larvae was intensely exsudative, with prompt afflux of neutrophils and progressive increase in eosinophils that was very evident from the 5th day PI. Neutrophils and eosinophils, which participate in the L. minor inflammatory infiltrate, are known to have very potent proteolytic enzymes. There is a correspondence between the finding of eosinophils in tissues, in this study and the increase in eosinophils levels in blood, as observed in another experimental study (Freire-Filha et al. 2001).

The predominance of eosinophils in the peripheral blood and in the tissue response to the helminth has been associated with a role in the defense against helminthic infections (Scott \& Sher 1993, Allen \& Maizels 1997). According to these authors, several cells participate in this phenomenon, such as macrophages, neutrophils, mast cells, basophils, and eosinophils. Eosinophils granules have been implicated as final mediators for the death of helminths. Although these issues were not the scope of this study, we can speculate that eosinophils and specific IgE may probably participate in protection to L. minor through antibody dependent cell mediated cytotoxicity. In fact, mechanisms of parasite destruction may operate in vivo since the number of nodules seen was much lower than the original innocula.

From the 13th day after inoculation, when the larvae or inflammatory response were observed, the granulomatous reaction had already been outlined, with epithelioid cells and fibrosis in the kidneys, lungs, and skeletal musculature. From the histological point of view, granulomas with similar features have been described in experimental murine schistosomiasis, in the form of aggregates of macrophages, eosinophils, lymphocytes, and fibroblasts (Brunet et al. 1998). In the murine model L. minor infection induced acute-phase lesions and progressive fibrosis and deposition of collagen during the chronic phase, similarly to what has been described in experimental murine schistosomiasis studies.

The findings of larval migration after hatching out in the intestine and free larvae in the hepatic parenchyma, pulmonary parenchyma, and skeletal musculature confirms earlier studies (Campos et al. 1989a, 1992, Volcan et al. 1992, Paçô \& Campos 1999). Also the kinetics of larval hatching in the intestine and findings of larvae in the liver, lungs and skeletal musculature have been confirmed.
Moreover, this study has demonstrated that third-stage larvae of $L$. minor use the hemolymphatic spaces in its invasive route.

Our findings are similar to those observed in infection by visceral migrans larvae, specifically, in regard to the passage of the larvae through the intestinal wall, as well as their localization in different organs such as the liver, lungs and skeletal musculature. Ingested embryonic eggs of Toxocara canis release larvae into the intestine. These larvae penetrate the intestinal wall and migrate via the lymphatics or the blood system to reach various organs, where they remain in the form of cysts or migrate onwards (Amato-Neto 1984). Our results indicate the possibility that, in the same way as T. canis, L. minor may also have a complex natural cycle.

The third-stage larvae of L. minor gave rise to cysts in the organs of mice used as experimental intermediate hosts, after the larvae have penetrated the ileocecal mucosa. The finding of larvae inside the portal vein and hepatic parenchyma right after inoculation provided evidence for the migration through the portal blood stream of third-stage larvae that hatched from eggs in the intestine. The presence of larvae in pancreatic and renal tissue, as well as in subcutaneous layers and the skeletal musculature, was suggestive of larval migration through the major circulation. The chronic inflammatory response, consisting of granulomas and fibrosis did not eliminate the parasite, which persisted and grew inside the nodules. The initial non-specific inflammatory reaction was not effective to stop the larval invasive process nor protected the host against infection. Various protective mechanisms from adaptative immune response may operate in vivo in order to enhance early inflammatory responses mediated through innate immunity. The characterization of such mechanisms deserves further investigations.

\section{ACKNOWLEDGMENTS}

To IPTSP-UFG technical-administrative personnel for their support in the animal's laboratory.

\section{REFERENCES}

Allen JE, Maizels RM 1997. Th1-Th2: reliable paradigm or dangerous dogma? Immunol Today 18: 387-392.

Amato Neto V 1984. Larvae migrans visceral. CCS 6: 46-47.

Brunet LR, Dunne DW, Pearce EJ 1998. Cytokine interaction and immune responses during Schistosoma mansoni infection. Parasitol Today 14: 422-427.

Campos DMB, Bressan MCRV, Rosa ZS 1989a. Considerações sobre a evolução de Lagochilascaris minor Leiper, 1909a. Número de mudas de larvas no interior do ovo. Rev Inst Med Trop São Paulo 22: 198.

Campos DMB, Freire-Filha, LG 1989b. Considerações sobre a evolução do Lagochilascaris minor LEIPER, 1909b. Susceptibilidade de diferentes linhagens de camundongos e hamsters a ovos embrionados do parasito. Rev Inst Med Trop São Paulo 22: 198.

Campos DMB, Freire-Filha LG, Vieira MA, Paçô JM, Maia MA 1992. Experimental life cycle of Lagochilascaris minor LEIPER, 1909. Rev Inst Med Trop São Paulo 34: 277 287.

Farah ARS, Moreira MAR, Santos ER, Zanini LA 1995. Cytologic diagnostic of lagochilascariasis. Case report. In XII 
International Congress of Cytology, Madrid, Spain, Abstract 39.

Fraiha H, Leão RNQ, Costa FSA 1989. Lagochilascaríase humana e dos animais domésticos. Zoon Rev Int 1: 25-33.

Freire-Filha LG, Kipnis APJ, Ribeiro WR, Campos DMB 2001.

Avaliação citohematológica em camundongos isogênicos da linhagem C57BL/6 infectados com Lagochilascaris minor. Rev Pat Trop 30: 225-234.

Leiper RT 1909. A new nematode worm from Trinidad, Lagochilascaris minor. Proc Zool Soc London 4: 742-743.

Paçô JM, Campos DMB 1999. Wild rodents as experimental intermediate host of Lagochilascaris minor (Leiper, 1909).
Mem Inst Oswaldo Cruz 94: 441-449.

Scott PA, Sher A 1993. Immunoparasitology. In WE Paul, Fundamental Immunology, Raven Press, New York, p. 11791210.

Smith JL, Bowman DD, Little MD 1983. Life cycle and development of Lagochilascaris sprenti (Nematoda: Ascarididae) from opossums (Marsupialia: Didelphidae) in Louisiana. J Parasitol 69: 736-745.

Volcán GS, Medrano CE, Payares G 1992. Experimental heteroxenous cycle of Lagochilascaris minor Leiper, 1909 (Nematoda: Ascarididae) in white mice and cats. Mem Inst Oswaldo Cruz 87: 525-532. 